mortality rate; I cannot. Can Dr Roberton quote any controlled study of present methods of neonatal intensive care to prove that expenditure in intensive care nurse:ies reduces both mortality and handicap in babies of very low birthweight? In order to forestall another tirade from him I hasten to assure you that he cannot.

It is right that some paediatricians responsible for newborn care who work in certain regions of the country where perinatal mortality is high (not East Anglia or the South East) should press for increased expenditure on staff and equipment if these are inadequate. It is also right that some paediatricians similarly involved in newborn care should try to review the subject dispassionately and not have their judgement influenced by medico-political considerations.

\section{Dickens, breath-holding, and The Hospital for Sick Children}

Sir,

Douglas Gairdner, in his account of breath-holding attacks as described in Our mutual friend, asks if the hospital to which Johnny was admitted was The Hospital for Sick Children, Great Ormond Street.

Charles Dickens was keenly interested in that hospital from its foundation in the early $1850 \mathrm{~s}$, and was concerned that it only had about 30 beds 6 years after it had opened. On 9 February 1858 he said that 'even that small number, so forlornly, so miserably diminuitive, compared with this vast London, cannot possibly be maintained unless the hospital be made better known...'

Dickens presided at a dinner at the Freemasons' Hall to raise subscriptions for the hospital and his speech makes moving reading; there is a copy in the library at Great Ormond Street, and in the Complete works of Charles Dickens. He was appointed an Honorary Governor, and gave a public reading of $A$ Christmas carol in aid of the hospital on 15 April 1858.

$$
\begin{array}{r}
\text { DAvid W Hide } \\
\text { The Green, } \\
\text { Shorwell, } \\
\text { Newport, } \\
\text { Isle of Wight PO30 3JG }
\end{array}
$$

\section{Depression in mothers of young children}

\section{Sir,}

Stephen Wolkind stated that nonclinicians are able to conduct standardised interviews. ${ }^{1}$ We use a microcomputer. We find that the computer is more consistent and reliable, and that it is also cheaper for it can be used for other tasks-such as data storage and statistical analysis. Furthermore there is evidence that patients answer computers more honestly than they answer doctors. ${ }^{2}$ Confidentiality is maintained because the information is inaccessible without knowledge of the computer program and possession of the data discs.
We have found that the Hamilton depression rating scale, widely used in psychiatry and considered a 'best buy', ${ }^{3}$ with the PET microcomputer, is simple to use and is well received by the subjects. This method was validated by the Institute of Psychiatry. ${ }^{4}$

So far our studies indicate that $28 \%$ of mothers of asthmatic children are depressed. Clinicians failed to identify half these mothers, so we disagree with $\mathrm{Dr}$ Wolkind that an idea of 'whether a parent may be clinically depressed can generally be obtained in a few minutes' by the paediatrician. We are currently extending our studies to other paediatric clinics and to general practice.

The microcomputer produces an assessment in only 10 minutes and can be used immediately before the medical consultation. This avoids the problem indicated by Dr Wolkind of attempting 'a sudden switch ... from asking about the child to conducting a mental state examination of the mother'. Thus the familie; in need of extra attention can be identified and the time riore profitably spent by the clinician in attempting to trea. the problem.

\section{References}

1 Wolkind S. Depression in mothers of young children. Arch Dis Child 1981; 56: 1-3.

2 Lucus R W, Mullin P J, Luna C B X, McInroy D C. Psychiatrists and a computer as interrogators of patients with alcohol-related illnesses: a comparison. $B r J$ Psychiatr 1977; 131: 160-7.

${ }^{3}$ Lader M. The clinical assessment of depression. Br J Clin Pharmacol 1981; 11: 5-14.

4 Carr A C, Gosh A, Ancill R J, Margo A. Assessment of depression by microcomputer. Acta Psychiatr Scand 1981; in press.

S J GOLDSWORTHY AND J O WARNER Brompton Hospital, Fulham Road, London SW3 $6 H P$ R J ANCILL Institute of Psychiatry, De Crespigny Park, London SE5 $8 A F$

\section{An improved sampling method to study the small intestinal microflora}

Sir,

To obtain samples of juice from the upper small-intestine for microbiological study, a sampling tube is normally passed perorally or pernasally into the stomach, and is allowed to advance into the duodenum, either by normal peristalsis or by manual guidance under fluoroscopic control. Bacterial contamination of the outside of the tube and the lumen inevitably occurs when openended sampling tubes are used and some organisms isolated from the small-intestine may therefore be contaminants arising from more proximal areas of the gastrointestinal tract. We describe a simple method to prevent such intralumenal contamination. 